\title{
Die toekoms van die drie Afrikaanse hoofstroomkerke saam
}

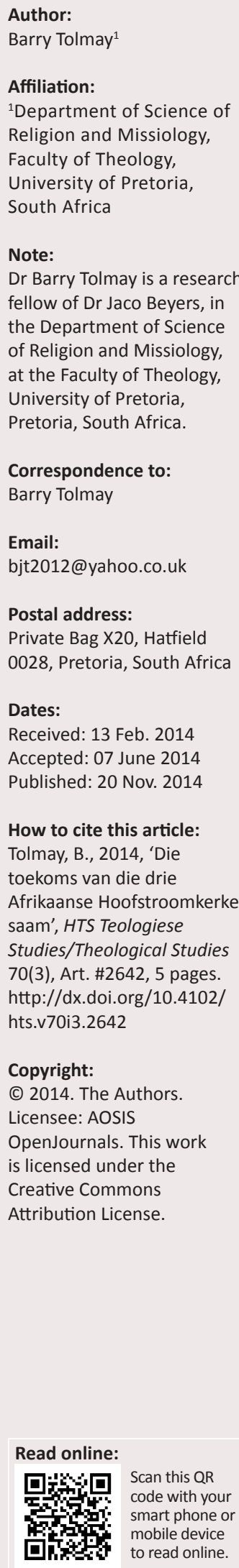

The future of the three mainstream Afrikaans Churches. The union of the three mainstream Afrikaans Churches encompasses inter alia a mutual origin, a mutual socio-historical contextualism, a mutual language experience and mutual Articles of Faith. These bonds form the foundation for greater cooperation and may even lead to future church unification. The Conventus of Reformed Churches is an exciting initiative that has developed over the last two decades. This organisation unites some 15 churches with a reformed background. Do the three Afrikaans mainstream churches take church unification seriously? Historically the Nederduitsche Hervormde Kerk van Afrika (NHKA) in particular was cautious about church unification. The Interdenominational Church Council (TKR) presents a basis for cooperation, but the question arises as to the structure that would be supported by the three churches. Mainly after 1994 the Afrikaner started redefining its own identity. The tendency is that the three churches will decrease in size as the three are all losing members. The three Afrikaans mainstream churches definitely need one another, and in future this interdependency probably will increase. That is why it is important to focus on common ground and not on differences. Bearing the church unification of the Protestant Church in the Netherlands (PCN) in mind, together we can look forward to a bright future in the 21st century.

\section{Inleiding}

Die geskiedenis van die drie Afrikaanse hoofstroomkerke, die Nederduitsche Hervormde Kerk van Afrika (NHKA), die Gereformeerde Kerke van Suid- Afrika (GKSA) en die Nederduitse Gereformeerde Kerk (NG Kerk) kom 'n lang pad saam en elke kerk se wortels is aan Nederland verbind. Die geskiedenis van die Nederlandse kerke met 'n Gereformeerde tradisie vertel 'n verhaal van kerkskeuring wat gedurende die negentiende en twintigste eeu plaasgevind het. Die vraag ontstaan of dit 'n invloed op ons situasie uitgeoefen het en of die drie Afrikaanse hoofstroomkerke die motivering het om te verenig.

Engelbrecht (1978:288) neem die standpunt in dat die verskeidenheid van drie Afrikaanse hoofstroomkerke nie as 'n sondige verskeurdheid beskou moet word nie. Hy meen die verskillende kerke het elkeen verskillende aksente. Dié sigbare werklikheid van geografie en instituut noodsaak hierdie verskeidenheid. Organisatoriese kerkeenheid sal volgens Engelbrecht (1978:288) nie wenslik wees nie, want indien almal in een instituut saamgevoeg word, beteken dit volgens hom dat almal eenders is. Is hierdie standpunt 36 jaar later nog aanwesig in die wandelgange van kerklike raadsale?

Die NG Kerk is egter baie duidelik oor die vereniging van die drie Afrikaanse hoofstroomkerke, soos verwoord in hul dokument Kerk en samelewing wat dit as 'n noodsaaklikheid stel:

Die afsonderlike bestaan van die drie Afrikaanse kerke is prinsipieel nie verantwoordbaar nie. Hulle het basies dieselfde belydenis; kerkregering en liturgie; hulle is saam in dieselfde land en vervul hulle roeping onder dieselfde volk; hulle bedieningsbehoeftes is in alle opsigte dieselfde. Daar bestaan dus geen deurslaggewende rede waarom die betrokke kerke nie tot 'n sigbare eenheid kan kom nie. (NG Kerk 1986:44)

Die historiese reis van die drie Afrikaanse hoofstroomkerke verskaf aan ons 'n sleutel om oor 'n moontlike toekoms saam te besin.

\section{Die historiese reis van die drie Afrikaanse hoofstroomkerke}

Die GKSA het in 1859 tot stand gekom. Op daardie staduim het die NHKA reeds bestaan (Van der Watt 1987:4). Hierdie twee kerke het nooit as kerke verenig nie. Dit was wel die NHKA en die NG Kerk wat in 1885 verenig het in die destydse Transvaal. Hierdie kerkvereniging het net 7 jaar geduur - tot 1892. Daar was reeds teen 1886 ernstige krake in die kerkvereniging aanwesig. Die verenigde kerk het tussen 1885 tot 1957 bekend gestaan as die Nederduits Hervormde of 
Gereformeerde Kerk. Die abortiewe kerkverenigingspoging het 'n duidelike letsel gelaat wat nog in 1986 opgemerk is. Botha (1986) merk op:

Sedert die Kerk 'n honderd jaar gelede deur 'n verkeerd gemotiveerde en kunsmatig bewerkte kerkvereniging ernstig geknou is, het die Kerk 'n baie versigtige houding ten opsigte van kerkvereniging ingeneem. (bl. 9)

Volgens Van der Watt (1987:142) het Ds L.E. Brandt, voorsitter van die Algemene Kerkvergadering van die NHKA, reeds in 1933 gevra dat 'n interkerklike kommissie tussen die drie Afrikaanse hoofstroomkerke in die lewe geroep word. Sy motivering was: 'So iets kan die belange van die volk en die saak van die Here dien en bevorder.'

\section{Die Interkerlike Kommissie}

Op 14 Maart 1939 het die Interkerklike Kommissie tot stand gekom. Die GKSA se sinodale byeenkoms het twee predikante aangewys, maar met die uitdruklike voorwaarde dat die GKSA homself nie gebonde ag deur advies of besluite van die Interkerklike Kommissie nie (Van der Watt 1987:143). Die Interkerlike Kommissie het oor geen administratiewe of wetgewende mag beskik nie.

Die NHKA was nie deel van die stigtingsvergadering nie. Volgens die kerk se 1938-standpunt was hulle nie ten gunste van 'n uitwendige, formele, organisatoriese vereniging nie (Borchardt 1974:197). Met die derde vergadering van die Interkerklike Kommissie in 1943 was die NHKA as lid teenwoordig en was al drie Afrikaanse hoofstroomkerke nou saam (Van der Watt 1987:144).

Van der Watt (1987:146) stel dit dat die Interkerklike Kommissie gereeld tussen 1941 en 1955 vergader het, waar sake van allerlei aard bespreek is: Sondagheiliging, huwelikswetgewing, lykverbranding, die Roomse gevaar, skoolraadsverkiesings, segregasie, gesamentlike eredienste, asook die kultuurstryd van die Afrikaner. Pont (1993:419) is van mening dat die Interkerklike Kommissie 'n groot bydrae gelewer het om beter begrip en samewerking tussen die drie Afrikaanse kerke op te bou omdat dit vir elkeen 'n saak van erns was. In 1955 het die Interkerklike Kommissie die Tussenkerklike Kommissie geword (Pont 1993:419).

\section{Die Tussenkerklike Kommissie}

Die Tussenkerklike Kommissie (TKK) het met die eerste vergadering in 1955 besluit dat hul minstens driejaarliks sal vergader (Pont 1993:419). Volgens die notule van die TKK (03 Junie 1958, Bylaag A) het die sinode van die GKSA in 1957 versoek dat die TKK daadwerklik kerkvereniging nastreef. In 1959 het daar egter tydens die eeufeesvieringe van die GKSA spanning tussen die GKSA en die NG Kerk ontstaan (Van der Watt 1987:150). Op 02 Mei 1961 het die NG Kerk en die GKSA in Bloemfontein vergader om 'n goeie gesindheid en samewerking te bevestig (Van der Watt 1987:150).

Tydens die NG Kerk se Algemene Sinode in 1966 is die volgende besluit goedgekeur:
Terwyl ons die historiese ontwikkelinge moet aanvaar dat daar drie Afrikaanse Kerke as afsonderlike kerke op dieselfde belydenisgrondslag bestaan, wil ons in gehoorsaamheid aan Gods Woord steeds daarna strewe om deur broederlike onderhandelinge en gesamentlike getuienis teen die bose mettertyd steeds hegter aansluiting tussen die Kerke te verwenenlik. (NG Kerk 1966:108-109)

In 1968 het die TKK besluit om spesifiek aandag te gee aan die betekenis van kerkbegrip asook die Skriftuurlike, leerstellige en kerkregtelike beginsels van ekumenisiteit (TKK-notule 13 Junie 1968). Volgens Pont (1993:421) was dit die eerste belangrike stap wat die TKK op die pad na kerkvereniging geneem het omdat memoranda tussen die kerke opgestel en uitgeruil is en indringende bilaterale gesprekke plaasgevind het. Die NHKA het gedurende die sewentigerjare standpunt ingeneem dat, as daar tussen die kerke 'n eenheid in die Waarheid bestaan, organisatoriese eenheid nie ' $n$ dwingende saak hoef te wees nie. Daarteenoor was dit die oortuiging van die GKSA en die NG Kerk dat die eenheid in die Waarheid in die eenheid van kerkverband sigbaar moet word (Pont 1993:421).

Gedurende die tagtigerjare het die TKK bevestig dat ' ... sy uiteindelike doelstelling eenwording van ons drie Afrikaanse kerke is' (TKK-notule, 23 Maart 1983). Van der Watt evalueer die drie Afrikaanse hoofstroomkerke soos volg:

Hierdie daadwerklike pogings tot gesprek tussen die drie Afrikaanse kerke stem tot dankbaarheid. Alhoewel daar niks gerealiseer is van die ideaal van een kerk nie, is die arbeid nie tervergeefs nie, want die diverse kerke staan ongetwyfeld nader aan mekaar as in vorige tye. (Van der Watt 1987:155)

Van die NHKA sluit Pont hierby aan as hy die TKK soos volg in die negentigerjare evalueer:

Gedurende die bietjie meer as vyf dekades van sy bestaan is merkwaardig baie gedoen om beter begrip tussen die drie Afrikaanse kerke te bewerkstellig en in stand te hou. Daarby kan ook gestel word dat die Tussenkerklike Kommissie ook die beweging na kerkvereniging lewend gehou en gestimuleer het. (Pont 993:424)

Die Algemene Sinodes van die NG Kerk van 1990, 1994 en 1998 het die TKK vir sy werk bedank en die versoek gerig dat samewerking met die NHKA en die GKSA op 'n plaaslike en streeksvlak sal plaasvind. Kerkrade, ringe en streeksinodes is versoek om gesamentlike eredienste, kanselruilings, samesprekings en gesamentlike projekte te hou (Du Toit $e t$ al. 2002:135-137).

In 2000 het die twee aparte afdelings binne die Fakulteit Teologie: Afdeling A van die NHKA en Afdeling B van die NG Kerk aan die Universiteit van Pretoria verenig. Met die totstandkoming van die veelkerklike fakulteit is akademiese samewerking tussen die NHKA en die NG Kerk bereik (Du Toit et al. 2002:139). In 2004 is die naam van die Tussenkerklike Kommissie na die Tussenkerklike Raad verander.

\section{Die Tussenkerklike Raad}

Dit is reeds 10 jaar sedert die Tussenkerklike Raad (TKR) tot stand gekom het. Geen noemenswaardige sukses is bereik om kerke te verenig nie. In Oktober 2013 het die NG 
Kerk se Algemene Sinode in Port Elizabeth die volgende aanbeveling goedgekeur:

Die besondere verhouding tussen die Nederduitse Gereformeerde Kerk, Nederduitsche Hervormde Kerk van Afrika en die Gereformeerde Kerke in Suid-Afrika, wat vanaf 1958 in die Tussenkerklike Kommissie en sedert 2004 in die Tussenkerklike Raad tot uitdrukking gekom het, het uit 'n gemeenskaplike reformatoriese herkoms 'n gesamentlike sosiohistoriese kontekstualiteit en 'n gemeenskaplike taal gegroei. Ondanks die verskeidenheid in kerkformasie en kerklike etos, asook graadverskille in die belewenis van die gemeenskaplike belydenis, het die kerkgenootskappe deur die jare op grond van'n gemeenskaplike groeibodem 'n verhouding van geloofseenheid in Christus gehandhaaf. Oortuig daarvan dat ons in Christus een is, is die Nederduitse Gereformeerde Kerk, Nederduitsche Hervormde Kerk van Afrika en die Gereformeerde Kerke in Suid-Afrika verbind tot kerkregtelik-verantwoorde samewerking tussen die drie kerke op bilaterale en/of trilaterale vlak. Die Algemene Sinode aanvaar dat hierdie oortuiging op gestruktureerde samewerking sal uitloop wat tot gestaltes van eenheid lei wat bepaalde organisatoriese konsekwensies mag hê. Die Algemene Sinode versoek dat die Tussenkerklike Raad binne bogenoemde uitgangspunt funksioneer en sy grondslag dienooreenkomstig wysig met instemming van die bevoegde kerklike vergaderings. Die Algemene Sinode versoek die TKR verder om aandag te gee aan die byeenbring van 'n breër groepering van kerke van die reformasie in 'n 'ekumenise sinode' wat as ruimte waarin eenheidsgesprekke kan plaasvind/ gefasiliteer word. Die Conventus, wat reeds 'n hele aantal kerke saambring, moet verkieslik hiervoor oorweeg word. Die Algemene Sinode dra dit aan die Moderamen op om die vordering te evalueer. Indien daar geen vordering is nie, moet die Moderamen die Algemene Sinode adviseer oor uittrede uit die TKR. (NG Kerk 2013:222; goedgekeur 08 Oktober 2013:15)

Daar is ' $n$ belangrike tendens wat tans waargeneem kan word ten opsigte van die drie Afrikaanse hoofstroomkerke. Daar begin ' $n$ ongemak by die NG Kerk ontstaan om alleen in 'n ekumeniese ligggaam te wees as dit net om historiese bande gaan. Die dilemma lê daarin dat dit om 'n primêr wit en Afrikaanse liggaam gaan. Die etiket van apartheid is histories om die drie Afrikaanse hoofstroomkerke gehang. Vele verwyte is oor baie jare teen die drie Afrikaanse hoofstroomkerke se ondersteuning van apartheid ingebring. Net lede van die drie Afrikaanse hoofstroomkerke kon lede van die Afrikaner-Broederbond wees (Serfontein 1982:206).

Daarom word hierdie band van herkoms in die bogestelde verklaring uitgespel: Gemeenskaplike reformatoriese herkoms, 'n gesamentlike sosio-historiese kontekstualiteit, 'n gemeenskaplike taal en 'n oortuiging dat ons in Christus een is. Hierdie bande vorm ' $n$ egte basis vir samewerking en selfs samesmelting in die toekoms.

Die versigtigheid wat tans by die NG Kerk bestaan, is gekoppel aan bilaterale ooreenkomste wat die NG Kerk oor die afgelope jare met byna al lidkerke van die Conventus van Reformatoriese kerke aangegaan het (NG Kerk 2013). In 'n bilaterale ooreenkoms kan spesifieke gemene gronde gevind word. Dit is toegespits op die dinamiese behoeftes van die twee kerke wat saamwerk. Dit is duidelik dat die NG Kerk sy toekoms in hierdie bilaterale ooreenkomste sien. Verder fokus die NG Kerk ook op deelname aan groter ekumeniese liggame soos die Suid-Afrikaanse Raad van Kerke en die Conventus van Reformatoriese Kerke.

Die GKSA het tydens hul Sinode in Januarie 2012 huiwering uitgespreek om 'n bilaterale ooreenkoms met die NG Kerk aan te gaan. Die motivering hiervoor is uiteengesit in Smit (2009:461) se drie ekumeniese sirkels wat by die GKSA bestaan. In die binneste sirkel bestaan korrespondensie en bestaan ekumeniese eenheid. Die GKSA het hierdie korrespondensie met veertien buitelandse kerke. Daar bestaan ekumeniese bande met die tweede sirkel. Die TKR, en gevolglik die NHKA en NG Kerk, pas hier in saam met die ander kerke wat deel van die Conventus van Reformatoriese Kerke is, asook die Afrikaanse Protestante Kerk (APK). Met kerke van die derde sirkel bestaan daar net ekumeniese kontak. Dr. Kobus Gerber, Algemene Sekretaris van die NG Kerk wat ekumeniese skakelwerk doen, was teleurgestel oor die houding van die GKSA (NG Kerk 2013:221). Tydens die volgende byeenkomste van die TKR is daar weer brûe tussen die NG Kerk en die GKSA gebou. Dit verklaar waarom die NG Kerk dit op die Algemene Sinode in 2013 aan sy Moderamen opgedra het om vordering in die TKR te evalueer. Die Moderamen moet vordering evalueer en die volgende Sinode oor moontlike uittrede uit die TKR adviseer.

\section{Die Conventus van Reformatoriese Kerke}

Hierdie opwindende inisiatief het oor die laaste twee dekades ontwikkel en in 1998 tot stand gekom. Die liggaam bind 'n vyftiental kerke van reformatoriese agtergrond saam. Binne hierdie ekumeniese inisiatief kry reformatoriese lidkerke saam die geleentheid om op uitdagings ten opsigte van hulle uitdagende rol in Suid-Afrika te kan fokus. Volgens Niemandt (2007:15) kan mense maklik leef asof die Christelike geloof steeds die amptelike geloof van die nasionale kultuur is.

Die Evangelies-Lutherse Kerk was die gasheer vir die 2012-vergadering in Kaapstad en die Uniting Presbyterian Church in Southern Africa die gasheer vir die 2013-vergadering in Johannesburg. Die Conventus het 'n besondere fokus op die betekenis en invloed wat Johannes Calvyn op reformasie in Suid-Afrika gemaak het. 2009 was die 500ste herdenkingsjaar van Calvyn se geboorte in 1509 . Die betekenis van die Heidelbergse Kategismus was die fokus van die 2013-Conventus-byeenkoms:

Die Conventus van Reformatoriese Kerke is ' $n$ belangrike ekumeniese brugbouer in Suid-Afrika. In ' $n$ snelveranderende Suid-Afrika waar hoofstroomkerke onder druk is, vorm dit ' $n$ belangrike anker. Dit is in die lig hiervan dat die NG Kerk by die Algemene Sinode in 2013 besluit het dat die Conventus die liggaam is waarop die NG Kerk meer fokus moet plaas deurdat die droom van groter eenheid binne die reformatoriese tradisie in SA 'n geruime tyd reeds op die NG Kerk se agenda is. (NG Kerk 2013:221)

Dit wil voorkom asof Gereformeerde ekumeniese liggame soos die Conventus van Reformatoriese Kerke in die afsienbare toekoms meer momentum sal kry. Deurdat 
hierdie inisiatief geleentheid gee vir lidkerke om te fokus op dit wat gemeenskaplik van belang is, maar lidkerke hul eie identiteit kan behou, skep dit die basis vir groei.

Ekumeniese liggame sal in alle waarskynlikheid individuele lidkerke tot groter bilaterale samewerking stimuleer. Die basis wat reeds vir goeie positiewe samewerking bestaan, toon belofte.

\section{Nuwe uitdagings in die toekoms vir die drie Afrikaanse hoofstroomkerke}

Verskeie faktore speel 'n rol om kerke van Gereformeerde grondslag onder druk te plaas. Dit is belangrik om raak te sien dat daar vanaf die twintigste tot die een-en-twintigste eeu 'n paradigmaskuif plaasgevind het. Niemandt (2007:14) stel dit dat die kerk vanuit die sentrum van die samelewing veral in Europa en die Verenigde State van Amerika (VSA) na die periferie geskuif het. In die proses maak Christenheid plek vir nuwe kulturele realiteite soos sekularisasie en godsdienstige pluralisme. Die einde van Christenheid is egter nie die einde van die Christelike geloof nie.

Ons is bewus daarvan dat die situasie in Suid-Afrika verander het. Dit wat in die konteks van 'die ou SuidAfrika' gefunksioneer het, is deur 'n paradigmaskuif na die 'nuwe Suid-Afrika' radikaal verander. Die drie Afrikaanse hoofstroomkerke het hul bevoorregte posisie en hegte verhouding met die staat verloor (Tolmay 1995:403).

Hierdie paradigmaskuif raak alle fasette van die samelewing, waarvan die volgende enkele voorbeelde is:

- Opgodsdienstige gebied neem alle godsdienste hul gelyke plek in by die staat. Dit sluit onder andere in Hindoeïsme, Boeddhisme, Islam en Tradisionele Afrika-godsdienste.

- Op onderwysgebied het baie radikale wysigings plaasgevind.

- Daar bestaan vryheid van eiendomsbesit en beweging nadat die Groepsgebiedwet afgeskaf is.

- Gesondheidsdienste het radikaal verander.

- Sekuriteit het verander en integrasie van die Weermag en Polisie het plaasgevind.

- Sportisolasie is opgehef en professionele sport kom algemeen voor.

- Ekonomies het groot skuiwe plaasgevind en SB word geïmplementeer.

- Massas blanke staatsamptenare word pakkette aangebied en vervang.

As alle samelewingsfere radikaal gewysig word en 'n nuwe paradigma ontstaan, impakteer dit ook op godsdiens en kerkwees. Die invloed van globalisering moet ook op kerkwees verdiskonteer word. Dit gaan verder 'n invloed in die een-en-twintigste eeu uitoefen. Die feit dat die media en kommunikasie radikaal verander het, beïnvloed ook kerkgangers en sal in die toekoms 'n nog groter invloed uitoefen. Niemandt (2007) stel die volgende mening:
Tradisionele kerke sukkel nogal om by hierdie veranderde en meestal chaotiese tye aan te pas. Dit lyk asof die gebruiklike antwoorde van die Christenheid die postmodernistiese mens eenvoudig nie meer tevrede stel nie. Kerkwees soos ons daarmee grootgeword het, werk nie meer nie. Baie keer is kerke se eerste reaksie op 'n nuwe wêreld om laer te trek. ... om nostalgies vas te klou aan die ou wêreld en steen en been te kla oor alles wat nuut en vreemd is. (bl. 37)

Volgens Naude gaan dit nie goed met die historiese hoofstroomkerke nie. Hy meen die hoofstroomkerke beleef vandag 'n tyd van verwarring en groot sosiale aanpassing onder sy lidmate, 'n aansienlike vermindering in getalle en meer beperkte invloed by die regering en in die samelewing (Naude 2005:13, 16).

Al bogenoemde sake oefen 'n invloed uit op hoe aanbid word en watter aksies in gemeentes bedryf word. Kerke en sinodes reageer verskillend op hierdie samelewingsinvloede. Hierdie reaksies beïnvloed uiteindelik in watter mate en of verskillende kerke in die toekoms gaan saamwerk. Buitendag en Van Wyk (2011) stel die volgende voor aan die NHKA:

Daarom benodig die NHKA ' $n$ herstelde en inklusiewe teologiese antropologie as onderbou van die ekklesiologie teenoor die gefragmenteerde ekklesiologie van die kerk se geskiedenis - 'n padversperring op die kerk se reis na inklusiwiteit. (bl. 27)

Smit stel die GKSA se motief tot kerkeenheid soos volg:

Die dryfveer om kerkgemeenskappe in eenheid saam te snoer - in die binneland en in die buiteland - was van vroeg af deel van die Gereformeerde kerkbeskouing. Die norm van hierdie dryfveer is kennelik nie kerklike gebruike (vanweë kultuursituering), of tyds- of plekbepaling nie, maar Skrifverankering. (Smit 2009:467)

Phyllis Tickle meen dat kerke uit verskillende kerklike tradisies besig is om nader aan mekaar te skuif. Dit is 'The great emergence' (Tickle 2008:131). Sy motiveer haar navorsing op verskeie gronde, maar meen dat die een-en-twintigste eeuse mens meer spiritueel is. Christene uit verskeie Christelike tradisies selekteer elemente van ander tradisies. Gevolglik kry mens kerse en liturgiese vernuwing by ander kerklike tradisies. Verder word waargeneem dat pastore uit die Pinkstergroepe meer studeer en groter klem op Woorduitleg plaas. NG Kerke het dikwels elemente van die gospel-musiek in hul eredienste.

Hoe hierdie aanpassing deur die onderskeie Afrikaanse hoofstroomkerke ontvang gaan word, het 'n groot invloed op die kerke se toekoms saam. Tickle (2008:136) beskryf ook 'n teenreaksie teen kerklike tradisies wat nader aan mekaar beweeg. In die VSA is hierdie reaksie by tussen $9 \%$ en $13 \%$ van lidmate waargeneem. In sulke gevalle tree kerkgroepe en persone in kerklike tradisies doelbewus 'n tree terug van samewerking. Volgens my behoort hierdie tendens ook in Suid-Afrika waargeneem te word.

Ten slotte kan gestel word dat die drie Afrikaanse hoofstroomkerke 'n lang historiese verbintenis het en dat al die kerke radikaal beïnvloed is deur paradigmaskuiwe 
met die totstandkoming van die Nuwe Suid-Afrika. Al drie Afrikaanse hoofstroomkerke het op verskillende wyses en op verskillende tye hul reis met apartheid afgesluit. Al drie Afrikaanse hoofstroomkerke is deel van ekumene op 'n internasionale vlak. Die NG Kerk het tydens hul Algemene Sinode van 2013 'n ekumeniese sinode in die vooruitsig gestel. Met hul lang reis saam behoort die NHKA en die GKSA die gesamentlike stigterslede van so 'n liggaam te wees. Die NHKA het by tye in die geskiedenis laat blyk dat kerkvereniging nie 'n voorkeur is nie. Daarvoor moet daar begrip wees nadat die kerkvereniging in 1885 nie uitgewerk het nie. Dieper teologiese gesprek en respek vir die NHKA se unieke tradisie bly die sleutel. Die GKSA het ook 'n ryk tradisie wat gekoester moet word.

Die drie Afrikaanse hoofstroomkerke het mekaar beslis nodig en sal in die toekoms mekaar nog meer nodig hê. Daarom is dit belangrik om nie op tegniese klein verskille te fokus nie, maar eerder op gemene grond. Deur kerkvereniging met die Protestante Kerk in Nederland (PKN) in gedagte kan ons saam 'n blink toekoms in die een-en-twintigste eeu ingaan ...

\section{Erkenning Mededingende belange}

Die outeur verklaar dat sy geen finansiële of persoonlike verbintenis het met enige party wat haar nadelig kon beïnvloed in die skryf van hierdie artikel nie.

\section{Literatuurverwysings}

Borchart, C., 1974, 'Die betrekkinge tussen die drie Afrikaanse kerke', Nederduitse Gereformeerd Teologiese Tydskrif XV(3), 181-203.

Botha, S. J., 1986, 'Is kerkvereniging vandag of in die toekoms 'n doelwit?', lesing gehou by die Kerkhistoriese Genootskap van die Nederduitsch Hervormde Kerk, NHKA, Pretoria.

Buitendag, J. \& Van Wyk, T., 2011 'Die NHKA op reis na inklusiwiteit 1: Die anatomie van ' $\mathrm{n}$ gefragmenteerde eskatologie', HTS Teologiese Studies/Theological Studies 67(3), 21-28. http://dx.doi.org/10.4102/hts.v67i3.1164

Du Toit, B., 2000, God? Geloof in 'n postmoderne tyd, CLF-Uitgewers, Bloemfontein.

Du Toit, F., Hofmeyer, H., Strauss, P. \& Van der Merwe, J., 2002, Die moeisame pad na vernuwing, Barnabas, Bloemfontein.

Engelbrecht, B.J., 1978, Teologie in die Kerk, HAUM, Pretoria.

Joubert, S. (red.), 2007, Die perfekte storm, CUM, Vereeniging.

Naude, P., 2005,Geesgedrewe gelowiges, Lux Verbi, Wellington.

Nederduitse Gereformeerde (NG) Kerk, (1966), Acta van die Algemene Sinode, Algemene Sinodale Kommissie, Kaapstad.

Nederduitse Gereformeerde (NG) Kerk, (1986), Kerk en samelewing, Algemene Sinodale Kommissie, Bloemfontein.

Nederduitse Gereformeerde Kerk, (2013), Agenda en notule van die Algemene Sinode, Algemene Sinodale Moderamen, Pretoria.

Niemandt, N., 2007, Nuwe drome vir nuwe werklikhede, Lux Verbi, Pretoria.

Pont, A.D., 1993, 'Die beweging vir kerkvereniging tussen die drie Afrikaanse gkriflig/In Luce Verbi 27(3), 415-426. http://dx.doi.org/10.4102/ids.v27i3.1470

Serfontein, J.H.P., 1982 Apartheid change and the NG Kerk, Taurus, Johannesburg.

Smit, C.J., 2009 'Kan die GKSA na 150 jaar beskou word as 'n stagnante kerkgemeenskap? Ekumenies beoordeel', In die Skriflig/In Luce Verbi 43(3), 447472. http://dx.doi.org/10.4102/ids.v43i3.232

Sweet, L., 2000 Learn to dance the soul salsa, Zondervan, Grand Rapids.

Tickle, P., 2008 The great emergence, Baker Books, Grand Rapids.

Tolmay, B.J., 1995 'Die Nederduitse Gereformeerde Kerk en die owerheid oor apartheid 1948-1991', doktorale proefskrif, Universiteit van Pretoria.

Tussenkerlike Kommissie (TKK), 1958, Notule: 03 Junie, Bylaag A.

Tussenkerlike Kommissie (TKK), 1968, Notule: 13 Junie.

Tussenkerlike Kommissie (TKK), 1983, Notule: 23 Maart.

Van der Watt, P.B., 1987, Die Nederduitse Gereformeerde Kerk 1905-1975, NGKB, Pretoria. 